\title{
Pulmonary hypertension in patients with combined pulmonary fibrosis and emphysema syndrome
}

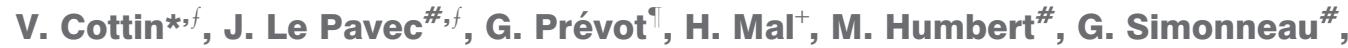 \\ J-F. Cordier* and GERM" $O$ " ${ }^{\S}$
}

ABSTRACT: This study aims to describe the haemodynamic and survival characteristics of patients with pulmonary hypertension in the recently individualised syndrome of combined pulmonary fibrosis and emphysema.

A retrospective multicentre study was conducted in 40 patients (38 males; age $68 \pm 9$ yrs; 39 smokers) with combined pulmonary fibrosis and emphysema, and pulmonary hypertension at right heart catheterisation.

Dyspnoea was functional class II in 15\%, III in 55\% and IV in 30\%. 6-min walk distance was $244 \pm 126 \mathrm{~m}$. Forced vital capacity was $86 \pm 18 \%$, forced expiratory volume in $1 \mathrm{~s} 78 \pm 19 \%$, and carbon monoxide diffusion transfer coefficient $28 \pm 16 \%$ of predicted. Room air arterial oxygen tension was $7.5 \pm 1.6 \mathrm{kPa}(56 \pm 12 \mathrm{mmHg})$. Mean pulmonary artery pressure was $40 \pm 9 \mathrm{mmHg}$, cardiac index $2.5 \pm 0.7 \mathrm{~L} \cdot \mathrm{min}^{-1} \cdot \mathrm{m}^{-2}$ and pulmonary vascular resistance $521 \pm 205 \mathrm{dyn} \cdot \mathrm{s} \cdot \mathrm{cm}^{-5} \cdot 1 \cdot \mathrm{yr}$ survival was $60 \%$. Higher pulmonary vascular resistance, higher heart rate, lower cardiac index and lower carbon monoxide diffusion transfer were associated with shorter survival.

Patients with combined pulmonary fibrosis and emphysema syndrome and pulmonary hypertension confirmed by right heart catheterisation have a dismal prognosis despite moderately altered lung volumes and flows and moderately severe haemodynamic parameters.

KEYWORDS: Chronic obstructive pulmonary disease, disproportionate, emphysema, pulmonary fibrosis, pulmonary hypertension, tobacco smoking

diopathic pulmonary fibrosis (IPF) is a severe chronic disease of unknown aetiology, with a median survival of 3 yrs. In smokers, some emphysema may be associated with IPF [1-3]. We recently individualised the syndrome of combined pulmonary fibrosis and emphysema (CPFE) [4] based on high-resolution computed tomography (HRCT) of the chest in a homogeneous group of 61 patients, further characterised by severe dyspnoea on exertion, subnormal spirometry, severe impairment of gas exchange and a median survival of $6.1 \mathrm{yrs}$ [5]. CPFE is probably related to tobacco smoking, a common risk factor for both emphysema and fibrosis (with odds ratios of up to 3.6 in familial fibrosis) [6, 7].

Patients with advanced IPF have a high prevalence of pulmonary hypertension $[8,9]$, with 31$46 \%$ of patients with mean pulmonary arterial pressure $(P$ pa $)>25 \mathrm{mmHg}$ at right-sided heart catheterisation (RHC) at evaluation for lung transplantation [9-12] and $86 \%$ at the time of transplantation [13]. Similarly, the prevalence of pulmonary hypertension (defined by mean $P$ pa $>20 \mathrm{mmHg}$ ) in patients hospitalised for chronic obstructive pulmonary disease (COPD) is $~ 50 \%$ [14], and may be as high as $50-90 \%$ in COPD patients evaluated for lung volume reduction surgery or lung transplantation $[15,16]$. The pejorative prognostic significance of pulmonary hypertension has been demonstrated in both IPF $[9,10,17]$ and COPD [18].

Two studies have reported that pulmonary hypertension is frequent in patients with the CPFE syndrome $[5,19]$, with $47 \%$ of patients with estimated systolic right ventricular pressure $\geqslant 45 \mathrm{mmHg}$ at echocardiography [5]. The risk of developing pulmonary hypertension is much higher in CPFE than in IPF without emphysema

For editorial comments see page 9.

AFFILIATIONS

*Hospices civils de Lyon, Hôpital Louis Pradel, Service de pneumologie - Centre de référence des maladies pulmonaires rares, Université de Lyon, Université Lyon I, UCBL-INRA-ENVL-EPHE, UMR754, IFR128, Lyon,

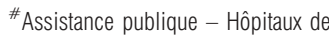
Paris, Hôpital Antoine Béclère, Service de pneumologie et réanimation, Centre de Référence de I'hypertension artérielle pulmonaire, Université Paris sud 11, Clamart,

- Service de pneumologie, Hôpital Larrey, Toulouse,

${ }^{+} \mathrm{CHU}$ Bichat, Paris, France.

${ }^{\S}$ A list of contributors from the Groupe d'Etudes et de Recherche sur les Maladies "Orphelines"

Pulmonaires (GERM" $O$ "'P) and their affiliations can be found in the Acknowledgements section. ${ }^{f}$ Both authors contributed equally.

CORRESPONDENCE

J-F. Cordier

Hôpital Louis Pradel 69677 Lyon (Bron) Cedex France

E-mail: jean-francois.cordier@chulyon.fr

Received:

March 072009

Accepted after revision: July 182009

First published online: July 302009 
(OR 19, 95\% CI 5.1-68.7) [19]. The prognosis of CPFE is worse than that of IPF without emphysema, an outcome determined by severe pulmonary hypertension and not only by the presence of associated emphysema [19]. Indeed, pulmonary hypertension is associated with an increased risk of death in CPFE (hazard ratio 4.03), with 5-yr probability of survival of $25 \%$ in patients with pulmonary hypertension at echocardiography compared with $75 \%$ in those without pulmonary hypertension at diagnosis [5]. CPFE syndrome has been included in the updated clinical classification of the aetiology of pulmonary hypertension under the category (3.3) of lung disease characterised by a mixed obstructive and restrictive pattern [20]. However, pulmonary hypertension was evaluated by echocardiography only in both studies $[5,19]$ as haemodynamic analysis is not yet available for CPFE. Thus, the objective of the present study was to describe the haemodynamic characteristics and their relationship to survival in patients with CPFE and pre-capillary pulmonary hypertension demonstrated by RHC.

\section{PATIENTS AND METHODS Study design}

This retrospective multicentre study was conducted by the French reference centre for rare pulmonary diseases (coordinator, J-F. Cordier), the French reference centre for pulmonary hypertension (coordinator, G. Simonneau) and the Groupe d'Etudes et de Recherche sur les Maladies "Orphelines" Pulmonaires (GERM“' $\mathrm{O}^{\prime \prime} \mathrm{P}$ ), a collaborative group dedicated to the study of rare (so-called "orphan") pulmonary diseases. Following the previous study [5], all participating physicians of the group were asked to prospectively report all cases of $\mathrm{CPFE}$ to the GERM“'O'P registry, and were advised to perform at least yearly screening for pulmonary hypertension using echocardiography. RHC was performed at the discretion of the physician in cases of suspected severe pulmonary hypertension. Only cases with pre-capillary pulmonary hypertension confirmed at RHC were included, and clinical data were then collected retrospectively. Data collection ended in December 2008. HRCT scans were reviewed by two of us (V. Cottin and J-F. Cordier) to validate the imaging diagnostic criteria.

According to French legislation, the agreement of an ethics committee and informed consent are not required for retrospective collection of data corresponding to current practice. However, the database was anonymous and complied with the restrictive requirements of the Commission Nationale Informatique et Liberté, the organisation dedicated to privacy, information technology and civil rights in France. This study was approved by our institutional review board.

\section{Inclusion criteria}

The following criteria were required for inclusion.

1) Modified American Thoracic Society/European Respiratory Society criteria for the diagnosis of IPF [21], with exclusion of other known causes of interstitial lung disease, such as certain drug toxicities, environmental exposures and connective tissue diseases; impaired gas exchange (increased alveolar-arterial oxygen tension difference, decreased arterial oxygen tension with rest or exercise or decreased diffusing capacity of the lung for carbon monoxide $(D \mathrm{~L}, \mathrm{CO})$ ); bibasilar reticular abnormalities with basal and subpleural predominance, traction bronchiectasis and/or honeycombing, and with minimal ground-glass opacities on HRCT scan; transbronchial lung biopsy or bronchoalveolar lavage showing no features to support an alternative diagnosis; and at least three of the following: age $>50 \mathrm{yrs}$, insidious onset of otherwise unexplained dyspnoea on exertion, duration of illness $>3$ months, bibasilar inspiratory crackles (dry or "velcro"-type in quality). As opposed to IPF criteria [21], evidence of restriction (reduced vital capacity) may or may not be present.

2) Presence of conspicuous emphysema (centrilobular and/or paraseptal) on HRCT scan, defined as well-demarcated areas of low attenuation delimitated by a very thin wall $(>1 \mathrm{~mm})$ or no wall.

3) Pre-capillary pulmonary hypertension defined by mean $P$ pa $>25 \mathrm{mmHg}$ at rest, with pulmonary arterial wedge pressure $<15 \mathrm{mmHg}$ and pulmonary vascular resistance (PVR) $>240$ dyn $\cdot \mathrm{s} \cdot \mathrm{cm}^{-5}$ at RHC $[22,23]$.

Patients with connective tissue disease, hypersensitivity pneumonitis, drug-induced lung disease and pneumoconiosis were excluded from this study. Patients with pulmonary arterial hypertension related to portal hypertension, congenital heart disease, HIV infection, anorexigen exposure, and patients with pulmonary hypertension due to left heart disease and chronic thromboembolic pulmonary hypertension were excluded.

\section{Investigations}

We reviewed the medical records to collect information using a standardised form. The 6-min walk test (6MWT) and pulmonary function tests were performed according to recommendations [24, 25]. RHC was performed as described [26]. Date of diagnosis was defined as the date of RHC, and all data (symptoms, 6MWT, pulmonary function and echocardiography) were obtained at the time of the RHC. In the absence of guidelines on the treatment of pulmonary hypertension associated with parenchymal pulmonary diseases, treatment was left at the discretion of the physician, and included oral anticoagulation, diuretics, oxygen as needed and possible pulmonary arterial hypertension-specific therapy initiated after the RHC.

\section{Statistical analysis}

Microsoft Excel 2003 and SPSS 16.0 (SPSS, Chicago, IL, USA) were used for data analysis. All values were expressed as mean \pm SD. Two-tailed p-values $<0.05$ were considered statistically significant. Estimation of the probability of survival at each time point was performed using the Kaplan-Meier method, from the date of the first haemodynamic evaluation demonstrating pulmonary hypertension, to the end-points of death or censoring. All-cause mortality was used in survival statistics. Transplanted subjects were censored at the time of transplantation. Surviving patients were censored at the date of the last visit. Comparisons of survival were performed using the log rank test. The relationship between survival and selected baseline variables was examined for each variable using univariate analysis of hazard ratios based on the proportional hazards model. 


\section{RESULTS}

\section{Patient population}

The study population included 40 patients (38 males and two females), with a mean \pm SD age of $68.2 \pm 8.9$ yrs. Three patients had been included in a previous study [5]. The mean delay between the first respiratory symptoms and the diagnosis of CPFE was $37 \pm 66$ months. All patients except one were current or ex-smokers. One patient was exposed to agrochemical compounds. 13 patients (32\%) had a history of atherosclerotic coronary artery disease and three $(7 \%)$ of peripheral artery disease.

Baseline demographic and clinical data are shown in table 1. Six patients $(15 \%)$ had chronic bronchitis. 11 patients $(27 \%)$ had clinical signs of right heart failure, two (5\%) had a history of syncope. Finger clubbing was reported in 23 patients $(57 \%)$ and basal crackles were present in 34 patients (85\%).

Histopathology of the lungs available in six cases demonstrated a pattern of usual interstitial pneumonia and emphysema in all cases. The serum level of $\alpha_{1}$-antitrypsin measured in 14 cases was normal.

\begin{tabular}{|c|c|c|}
\hline TABLE 1 & \multicolumn{2}{|c|}{$\begin{array}{l}\text { Characteristics, clinical manifestations, and } \\
\text { pulmonary function tests at diagnosis in patients } \\
\text { with combined pulmonary fibrosis and } \\
\text { emphysema syndrome }\end{array}$} \\
\hline \multicolumn{3}{|l|}{ Variables } \\
\hline \multicolumn{2}{|c|}{ Sex male/female $n$} & $38 / 2$ \\
\hline \multicolumn{2}{|c|}{ Age yrs } & $68.2 \pm 8.9(47.7-82.2)$ \\
\hline \multicolumn{2}{|c|}{ Current/ex/never-smokers n } & $2 / 37 / 1$ \\
\hline \multicolumn{2}{|c|}{ Smoking history pack-yrs } & $46 \pm 23(17-120)$ \\
\hline \multicolumn{2}{|c|}{ NYHA class I } & 0 \\
\hline \multicolumn{2}{|c|}{ NYHA class II } & $6(15)$ \\
\hline \multicolumn{2}{|c|}{ NYHA class III } & $22(55)$ \\
\hline \multicolumn{2}{|c|}{ NYHA class IV } & $12(30)$ \\
\hline \multicolumn{2}{|c|}{ 6MWD m } & $244 \pm 126(78-689)$ \\
\hline \multicolumn{2}{|c|}{ 6MWT $S p, O_{2}$ at end of test } & $77 \pm 10(62-96)$ \\
\hline \multicolumn{2}{|c|}{ 6MWT $\mathrm{Sp}, \mathrm{O}_{2}$ decrease during test } & $-15 \pm 8(-30--1)$ \\
\hline \multicolumn{2}{|c|}{ FVC \% pred } & $86 \pm 18(46-116)$ \\
\hline \multicolumn{2}{|l|}{ FEV $1 \%$ pred } & $78 \pm 19(38-114)$ \\
\hline \multicolumn{2}{|l|}{ FEV $1 /$ FVC \% } & $75 \pm 18(29-107)$ \\
\hline \multicolumn{2}{|l|}{ TLC \% pred } & $84 \pm 23(47-139)$ \\
\hline \multicolumn{2}{|l|}{ RV \% pred } & $87 \pm 47(41-219)$ \\
\hline \multicolumn{2}{|c|}{$D$ L,co \% pred } & $24 \pm 14(3-52)$ \\
\hline \multicolumn{2}{|c|}{ Kco \% pred } & $28 \pm 16(4-68)$ \\
\hline \multicolumn{2}{|c|}{$\mathrm{Pa}, \mathrm{O}_{2}$ at rest $\mathrm{kPa}$} & $7.5 \pm 1.6(5.2-11.7)$ \\
\hline \multicolumn{2}{|c|}{$\mathrm{Pa}, \mathrm{O}_{2}$ at rest $\mathrm{mmHg}$} & $56.2 \pm 12.0(39-84)$ \\
\hline \multicolumn{2}{|c|}{$\mathrm{Pa}, \mathrm{CO}_{2}$ at rest $\mathrm{kPa}$} & $4.7 \pm 0.6(3.3-5.9)$ \\
\hline \multicolumn{2}{|c|}{$\mathrm{Pa}, \mathrm{CO}_{2}$ at rest $\mathrm{mmHg}$} & $35.2 \pm 4.5(25-44)$ \\
\hline
\end{tabular}

Data are presented as mean \pm SD (range) or $n(\%)$, unless otherwise stated. NYHA: New York Heart Association; 6MWD: 6-min walk distance; 6MWT: 6-min walk test; $\mathrm{Sp}, \mathrm{O}_{2}$ : peripheral oxygen saturation; FVC: forced vital capacity; \% pred: \% predicted; FEV1: forced expiratory volume in $1 \mathrm{~s}$; TLC: total lung capacity; RV: residual volume; $D \mathrm{~L}, \mathrm{CO}$ : single-breath diffusing capacity of the lung for carbon monoxide; $\mathrm{KCO}$ : single breath transfer factor of the lung for carbon monoxide; $\mathrm{Pa} \mathrm{O}_{2}$ : arterial oxygen tension; $\mathrm{Pa}_{2} \mathrm{CO}_{2}$ : arterial carbon dioxide tension.

\section{Functional evaluation and haemodynamics}

New York Heart Association (NYHA) functional class was III or IV in $85 \%$ of the patients. 6 -min walk distance (6MWD) was $244 \pm 126 \mathrm{~m}$.

The mean delay between the diagnosis of CPFE and the RHC demonstrating pulmonary hypertension was $16 \pm 25$ months, and the mean delay between the first respiratory symptoms and the diagnosis of pulmonary hypertension was $53 \pm$ 66 months. Results of RHC are presented in table 2. 6MWD was $314 \pm 153 \mathrm{~m}$ in patients with NYHA functional class II, $255 \pm 126 \mathrm{~m}$ in class III and $180 \pm 91 \mathrm{~m}$ in class IV. Haemodynamic measurements showed a mean $P$ pa of $40 \pm 9 \mathrm{mmHg}$, and PVR of $521 \pm 205$ dyn.s.cm ${ }^{-5}$. Mean Ppa, cardiac index and PVR did not significantly correlate with forced vital capacity (FVC), $D \mathrm{~L}, \mathrm{CO}$ or transfer factor of the lung for carbon monoxide (KCO).

In 27 patients $(68 \%)$, the mean $P$ pa was $>35 \mathrm{mmHg}$ (and $>40 \mathrm{mmHg}$ in $48 \%$ ), with a mean $P$ pa of $45 \pm 6 \mathrm{mmHg}$, PVR of $603 \pm 181 \mathrm{dyn} \cdot \mathrm{s} \cdot \mathrm{cm}^{-5}$, cardiac index of $2.5 \pm 0.7 \mathrm{~L} \cdot \mathrm{min}^{-1} \cdot \mathrm{m}^{-2}$ and $6 \mathrm{MWD}$ of $231 \pm 105 \mathrm{~m}$.

Echocardiography showed dilated right cardiac cavities in $77 \%$ of cases, with paradoxical movement of the interventricular septum in $32 \%$ of the cases. Estimated systolic Ppa was $67 \pm 15 \mathrm{mmHg}$ (range 20-100; $\mathrm{n}=36$ ) and was $35 \mathrm{mmHg}$ or higher in $97 \%$ of patients. Pericardial effusion was not reported. The B-type natriuretic peptide level available for 14 patients was $340 \pm 298 \mathrm{pg} \cdot \mathrm{mL}^{-1}$ (normal $<100 \mathrm{pg} \cdot \mathrm{mL}^{-1}$ ).

Mean values of lung volumes were within normal limits, contrasting with severely impaired gas exchange (mean KCO was $28 \pm 16 \%$ of predicted) (table 1 ).

\section{Outcome and survival analysis}

Patients were followed for a median of $8 \pm 8$ months (range 134 months). Treatment of pulmonary hypertension, pulmonary

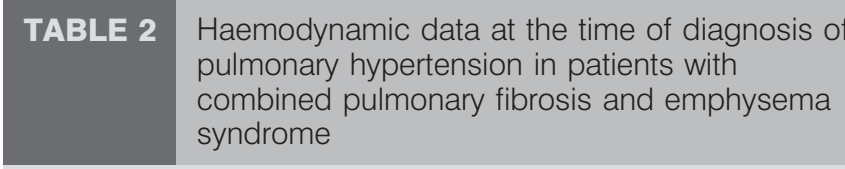

\section{Variables}

\begin{tabular}{|c|c|}
\hline fc beats $\cdot \mathrm{min}^{-1}$ & $78 \pm 15(50-112)$ \\
\hline Pra $\mathrm{mmHg}$ & $7 \pm 4(0-18)$ \\
\hline Mean Ppa $\mathrm{mmHg}$ & $40 \pm 9(24-56)$ \\
\hline Diastolic Ppa $\mathrm{mmHg}$ & $26 \pm 6(15-40)$ \\
\hline Systolic Ppa mmHg & $64 \pm 14(39-90)$ \\
\hline Ppaw $\mathrm{mmHg}$ & $10 \pm 3(2-14)$ \\
\hline $\mathrm{CO} L \cdot \mathrm{min}^{-1}$ & $4.7 \pm 1.3(2.8-7.6)$ \\
\hline $\mathrm{CI} L \cdot \mathrm{min}^{-1} \cdot \mathrm{m}^{-2}$ & $2.5 \pm 0.7(1.5-4.4)$ \\
\hline PVR dyn $\cdot \mathbf{s} \cdot \mathrm{cm}^{-5}$ & $521 \pm 205(240-1040)$ \\
\hline PVRi dyn $\cdot \mathrm{s} \cdot \mathrm{cm}^{-5} \cdot \mathrm{m}^{-2}$ & $947 \pm 401(360-1912)$ \\
\hline Sv, $\mathrm{O}_{2} \%$ & $65 \pm 9(47-86)$ \\
\hline
\end{tabular}

Data are presented as mean \pm SD (range). $f C$ : cardiac frequency; Pra: right atrial pressure; Ppa: pulmonary arterial pressure; Ppaw: pulmonary arterial wedge pressure; CO: cardiac output; $\mathrm{Cl}$ : cardiac index; PVR: pulmonary vascular resistance; PVRi: pulmonary vascular resistance index; $\mathrm{SV}, \mathrm{O}_{2}$ : venous oxygen saturation. 
fibrosis and emphysema is shown on table $3.92 \%$ of the patients received long-term oxygen therapy. 24 patients (60\%) received first-line therapy for pulmonary hypertension with bosentan, sildenafil or inhaled iloprost after RHC and were evaluated after 3-6 months. No statistically significant effect of treatment was observed regarding NHYA class, 6MWD or estimation of systolic $P$ pa at echocardiography.

At the end of the follow-up period, six patients $(15 \%)$ had developed acute right heart failure, 14 (35\%) had died, none had been lost to follow-up and four $(10 \%)$ had been transplanted. The overall survival rate at 1 yr was $60 \pm 10 \%$ (fig. 1). Death was due to hypoxaemia and chronic respiratory failure as a result of pulmonary hypertension and CPFE in 10 cases, cancer in three patients (lung, $n=2$; throat, $n=1$ ) and septic shock in one patient. A higher survival rate was observed in patients with $D \mathrm{~L}, \mathrm{CO}$ higher than the median value of $22 \%$ pred than in those with lower DL,CO (estimated 1-yr survival of $79.5 \pm 13.1 \%$ versus $43.5 \pm 18 \%$; $p=0.046)$; in patients with PVR lower than the median value of $485 \mathrm{dyn} \cdot \mathrm{s} \cdot \mathrm{cm}^{-5}$ (1-yr estimate of survival of $100 \%$ versus $47.6 \pm 15.1 \% ; p=0.008)$; and in patients with a cardiac index higher than the median value of $2.4 \mathrm{~L} \cdot \mathrm{min}^{-1} \cdot \mathrm{m}^{-2}(1-\mathrm{yr}$ survival of $79.1 \pm 13.8 \%$ versus $45.8 \pm 14.2 \%$; $p=0.044)$. 10 of 20 patients with cardiac index $<2.4 \mathrm{~L} \cdot \mathrm{min}^{-1} \cdot \mathrm{m}^{-2}$ died, compared with two of the 20 patients with a cardiac index $>2.4 \mathrm{~L} \cdot \mathrm{min}^{-1} \cdot \mathrm{m}^{-2}$ $(\mathrm{p}=0.01)$. The median survival in patients with cardiac index $<2.4 \mathrm{~L} \cdot \mathrm{min}^{-1} \cdot \mathrm{m}^{-2}$ was only 7.5 months (95\% CI 1.2-13.9 months), and the median survival in patients with PVR $>485 \mathrm{dyn} \cdot \mathrm{s} \cdot \mathrm{cm}^{-5}$ was 6.6 months (95\% CI 5.2-8.0 months). Nonsignificant trends for higher survival rate were observed in patients with higher transfer coefficient, lower mean $P$ pa, higher 6MWD and NYHA class II or III.

The results of the univariate analysis relating survival time to clinical, functional and haemodynamic characteristics measured at baseline in the overall population are shown in table 4 . High mean Ppa, high PVR, high heart rate and low DL,CO were significantly associated with a poor outcome. In addition, there

\begin{tabular}{|c|c|c|}
\hline TABLE 3 & \multicolumn{2}{|c|}{$\begin{array}{l}\text { Treatment in } 40 \text { patients with combined } \\
\text { pulmonary fibrosis and emphysema syndrome } \\
\text { and pre-capillary pulmonary hypertension }\end{array}$} \\
\hline \multicolumn{3}{|c|}{ Treatment of pulmonary hypertension } \\
\hline Diuretics & & $30(75)$ \\
\hline Oral antico & julant & $19(47)$ \\
\hline Bosentan & & $12(30)$ \\
\hline Sildenafil & & $11(27)$ \\
\hline Inhaled ilop & & $1(2)$ \\
\hline \multicolumn{3}{|c|}{ Treatment of pulmonary fibrosis } \\
\hline Oral corticc & teroids & $16(40)$ \\
\hline$N$-acetylcys & & $9(22)$ \\
\hline Azathioprin & & $4(10)$ \\
\hline \multicolumn{3}{|c|}{ Treatment of emphysema } \\
\hline Inhaled bro & chodilators & $23(57)$ \\
\hline Inhaled cor & osteroids & $17(42)$ \\
\hline Long-term o & gen & 37 (92) \\
\hline Pulmonary $t$ & nsplantation & $4(10)$ \\
\hline
\end{tabular}

was a trend for a poor outcome in patients with NYHA functional class IV, lower KCO and lower cardiac index. Similar results were obtained when selected numerical variables (mean Ppa, cardiac index and PVR) were treated as nonlinear and separated into two categories or into four quartiles (data not shown). No significant effect of therapy was observed in patients who received medical treatment for pulmonary hypertension compared with conventional therapy alone.

\section{DISCUSSION}

This is the first study of pulmonary hypertension confirmed by RHC in patients with CPFE.

CPFE is a distinct syndrome contrasting with both solitary IPF and emphysema by demonstrating relatively preserved lung volumes and airflow measurements, respectively [4]. It is associated with a poor outcome related to the high prevalence of pulmonary hypertension, a characteristic feature in the natural history of CPFE syndrome $[5,19]$. In this study, we showed that: 1) pulmonary hypertension was demonstrated at RHC with a mean delay of only 16 months after the diagnosis of CPFE at HRCT scan; 2) patients had severe dyspnoea (with $85 \%$ in functional class III or IV) and severe exercise limitation (with a mean 6MWD of $244 \pm 126 \mathrm{~m}$ ), despite subnormal spirometry and moderately severe haemodynamic parameters; 3) pulmonary hypertension in CPFE was associated with a dismal prognosis, with a $1-y r$ survival of only $60 \% ; 4$ ) a lower cardiac index, a lower transfer factor and increased PVR were associated with a shorter survival.

The pulmonary function characteristics of the patients included in the present study were strikingly similar to that of our previous report [5], although only three patients were included in both studies. This reproducibility underscores the clinical relevance of defining the syndrome of CPFE with simple diagnostic criteria, thus justifying our pragmatic approach based on the presence of conspicuous features of both emphysema and fibrosis on HRCT (e.g. noticeable without quantification of imaging features). Mean values of FVC, total lung capacity and forced expiratory volume in $1 \mathrm{~s}$ (FEV1) were normal, contrasting with severely impaired diffusion capacity of the lung, with mean values of $\mathrm{DL}, \mathrm{CO}$ and $\mathrm{KCO}$ of only $24 \%$ and $28 \%$ pred, respectively, and severe hypoxaemia in $92 \%$ of the patients. The severe impairment of diffusion capacity probably represents the additive or synergistic effects of emphysema, fibrosis and pulmonary vascular disease, and is one of the hallmarks of CPFE syndrome [27]. Most patients with CPFE syndrome were males, as previously shown [5, 19]. Pulmonary hypertension is present in $47-90 \%$ of patients with CPFE, based on echocardiographic measurement of right ventricular systolic pressure, and is associated with an increased risk of death $[5,19]$. Since only patients with precapillary pulmonary hypertension confirmed at RHC were included in this study, we could not further evaluate the proportion of CPFE patients with pulmonary hypertension or the proportion of patients with post-capillary pulmonary hypertension. Selection bias towards the most severe cases cannot be excluded. However, echocardiography especially lacks specificity and accuracy in patients with advanced lung disease, including COPD [28] and IPF [29, 30], frequently leading to overdiagnosis of pulmonary hypertension [29, 30]. The present study is the first to report on haemodynamic 


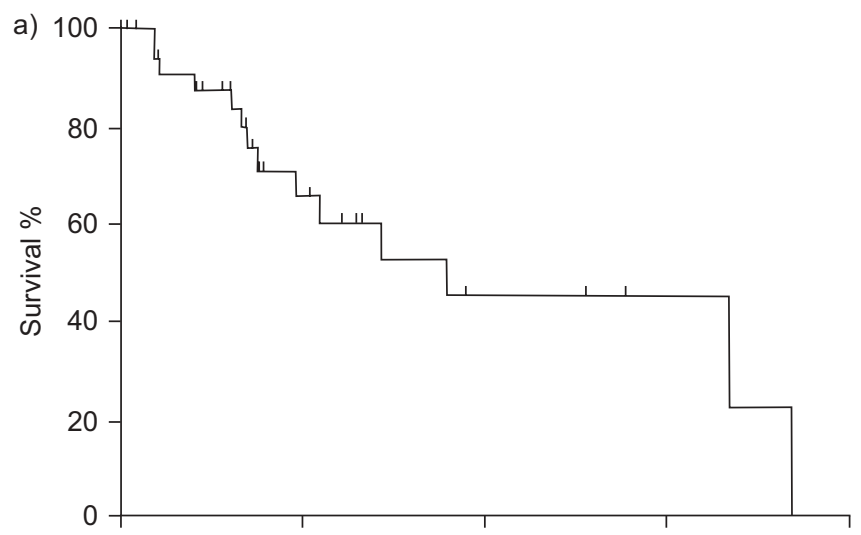

b)
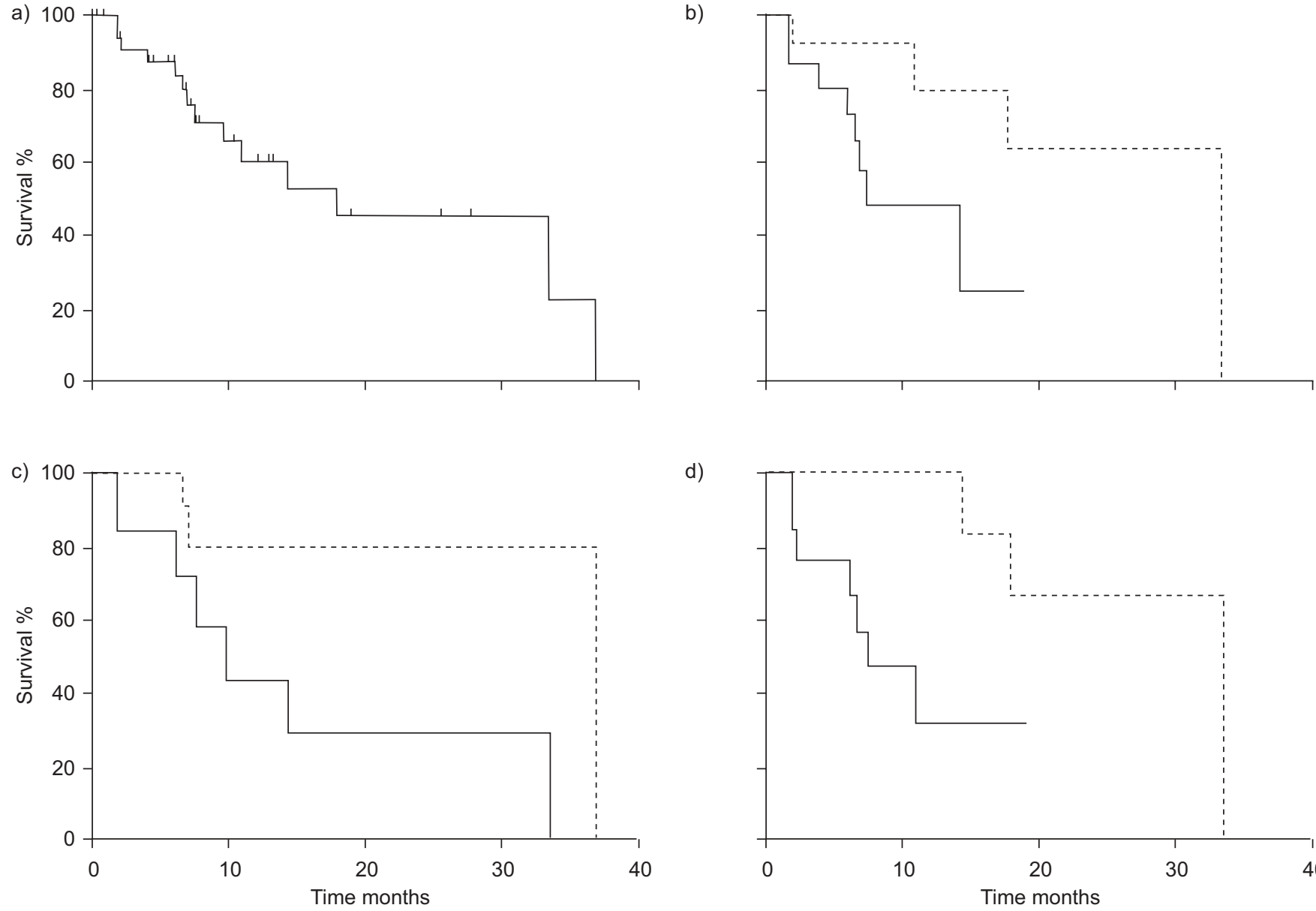

d)

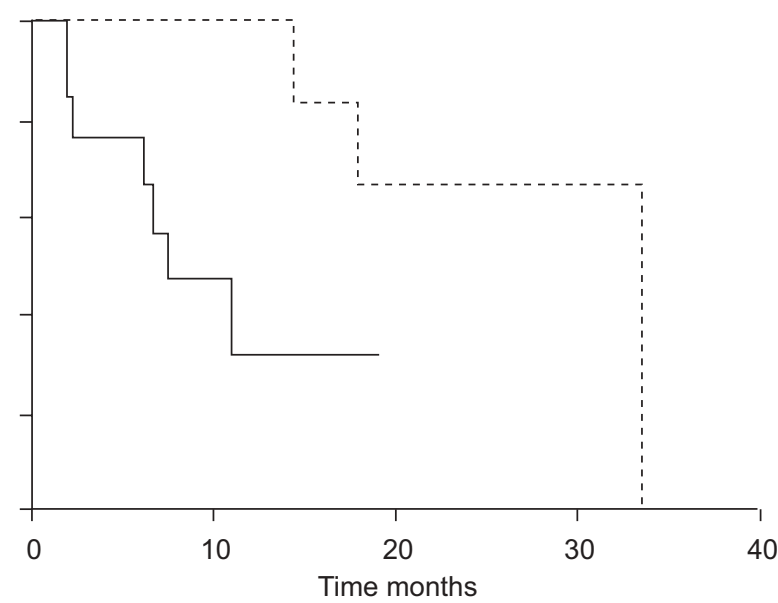

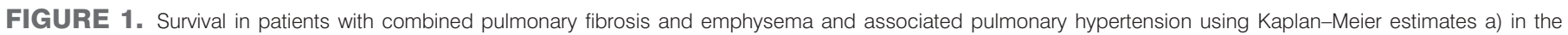

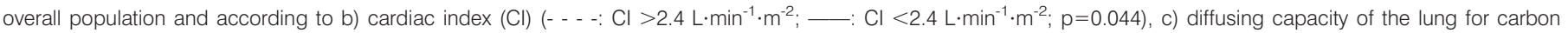

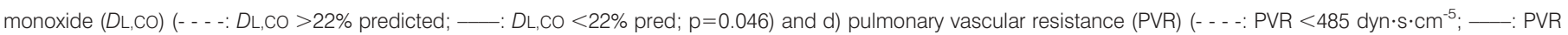
$>485$ dyn $\left.\cdot \mathrm{s} \cdot \mathrm{cm}^{-5} ; \mathrm{p}=0.008\right)$. Transplanted patients were censored at the time of transplantation. $\mathrm{Median} \mathrm{Cl} \mathrm{was} 2.4 \mathrm{~L} \cdot \mathrm{min}^{-1} \cdot \mathrm{m}^{-2}$.

evaluation in CPFE patients with pre-capillary pulmonary hypertension confirmed by RHC, the gold standard for the diagnosis of pulmonary hypertension, thus allowing prognostic analysis according to haemodynamic parameters. The delay in diagnosing pulmonary hypertension in patients with CPFE seemed to be mostly related to the natural history of disease, with pulmonary hypertension detected at echocardiography during follow-up; therefore, we perform echocardiography at least once a year in any patient with CPFE.

Although no formal comparison can be made from this retrospective analysis, it is noteworthy that patients with pulmonary hypertension and CPFE had a dismal prognosis, with a $60 \%$ probability of survival at $1 \mathrm{yr}$ from the diagnosis of pulmonary hypertension, similar to the probability of survival at $1 \mathrm{yr}$ of $72 \%$ in patients with IPF and associated pulmonary hypertension at RHC [10]. The reported median survival from the diagnosis is $\sim 3$ yrs in IPF [31] and 6 yrs in one series of CPFE $[5,19]$; however, survival from the diagnosis of fibrosis was lower in patients with CPFE than in those with IPF without emphysema when compared within a single institution, mostly due to a higher incidence of pulmonary hypertension at echocardiography in CPFE $[5,19]$. In contrast, the survival was $36 \%$ at 5 yrs in patients with COPD and pulmonary hypertension (mean $P$ pa $>25 \mathrm{mmHg}$ ) at onset of long-term oxygen therapy (Global Initiative for Chronic Obstructive Lung Disease IV) [18]. The 1-yr survival of incident cases of pulmonary arterial hypertension in the national French registry was $88 \%$, although with a worse haemodynamic profile than that of the present cohort (with a higher PVR index of $1,640 \mathrm{dyn} \cdot \mathrm{s} \cdot \mathrm{cm}^{-5} \cdot \mathrm{m}^{-2}$ and similar cardiac index of $2.5 \mathrm{~L} \cdot \mathrm{min}^{-1} \cdot \mathrm{m}^{-2}$ ) [32]. Thus, CPFE with associated pulmonary hypertension is a most severe condition with especially poor prognosis, worse than that of solitary COPD with associated pre-capillary pulmonary hypertension, and somewhat similar to that of IPF with pre-capillary pulmonary hypertension.

Pulmonary hypertension occurring in the context of chronic parenchymal lung disease is usually mild or moderate (i.e. with mean $P$ pa $<35-40 \mathrm{mmHg}$ ). Recently, attention has focused on a subgroup of COPD patients, with severe "out-of-proportion" pre-capillary pulmonary hypertension despite long-term oxygen therapy $[14,15,33]$, arbitrarily defined by mean $P$ pa $>35-$ $40 \mathrm{mmHg}$ [14]. These patients are prone to right heart failure and may share similarities with those with idiopathic pulmonary 


\begin{tabular}{|c|c|c|c|c|}
\hline \multirow{2}{*}{ TABLE 4} & \multicolumn{4}{|c|}{$\begin{array}{l}\text { Univariate analysis relating survival to selected } \\
\text { baseline variables }\end{array}$} \\
\hline & & Hazard ratio & $95 \% \mathrm{Cl}$ & p-value \\
\hline \multicolumn{2}{|l|}{ Age yrs } & 1.04 & $0.97-1.11$ & 0.297 \\
\hline \multicolumn{2}{|c|}{ NYHA class (II-III/IV) } & 2.25 & $0.86-5.87$ & 0.096 \\
\hline \multicolumn{2}{|c|}{$D L, C O \%$ pred } & 0.93 & $0.87-1.00$ & 0.049 \\
\hline \multicolumn{2}{|c|}{ Kco \% pred } & 0.94 & $0.88-1.01$ & 0.071 \\
\hline \multicolumn{2}{|l|}{$\mathrm{Pa}, \mathrm{O}_{2} \mathrm{kPa}$} & 0.80 & $0.35-1.84$ & 0.604 \\
\hline \multicolumn{2}{|c|}{ 6MWD m } & 0.99 & $0.99-1.00$ & 0.157 \\
\hline \multicolumn{2}{|c|}{$\mathrm{Sa}, \mathrm{O}_{2} 6 \mathrm{MWD} \%$} & 0.97 & $0.91-1.04$ & 0.444 \\
\hline \multicolumn{2}{|c|}{$f c$ beats $\cdot \min ^{-1}$} & 1.07 & $1.01-1.12$ & 0.010 \\
\hline \multicolumn{2}{|c|}{ Pra mmHg } & 0.99 & $0.84-1.17$ & 0.904 \\
\hline \multicolumn{2}{|c|}{ Mean Ppa mmHg } & 1.07 & $1.00-1.14$ & 0.049 \\
\hline \multicolumn{2}{|c|}{ CI L. $\min ^{-1} \cdot \mathrm{m}^{-2}$} & 0.23 & $0.05-1.02$ & 0.054 \\
\hline \multicolumn{2}{|c|}{ PVR dyn $\cdot \mathbf{s} \cdot \mathrm{cm}^{-5}$} & 1.01 & $1.00-1.01$ & 0.002 \\
\hline \multicolumn{2}{|c|}{$\mathrm{Sv}, \mathrm{O}_{2} \%$} & 1.02 & $0.95-1.10$ & 0.513 \\
\hline \multicolumn{2}{|c|}{ Medical treatment of $\mathrm{PH}$ (yes/no) } & 1.32 & $0.39-4.93$ & 0.656 \\
\hline
\end{tabular}

A value of hazard ratio $>1$ indicates an increased risk of death. NYHA: New York Heart Association; DL,CO: diffusing capacity of the lung for carbon monoxide; \% pred; \% predicted; KCO: transfer factor of the lung for carbon monoxide; $\mathrm{Pa}, \mathrm{O}_{2}$ : arterial oxygen tension; 6MWD: 6-min walk distance; $\mathrm{Sa}_{2} \mathrm{O}_{2}$ : arterial oxygen saturation; $f \mathrm{C}$ : cardiac frequency; Pra: right atrial pressure; $P$ pa: pulmonary arterial pressure; $\mathrm{Cl}$ : cardiac index; PVR: pulmonary vascular resistance; $\mathrm{SV}_{\mathrm{O}_{2}}$ : venous oxygen saturation; $\mathrm{PH}$ : pulmonary hypertension.

arterial hypertension [16]. Interestingly, $68 \%$ of the patients included in the present study had pulmonary hypertension that was disproportionate to the underlying parenchymal lung disease, with mean $P$ pa $>35 \mathrm{mmHg}$. The mean value of FVC was $86 \%$ pred in CPFE (compared with $49 \%$ pred in patients with IPF and associated pulmonary hypertension [10]), and the mean value of FEV1 was $78 \%$ (compared with $55 \%$ in patients with COPD and disproportionate pulmonary hypertension [14]).

Although the efficacy of drugs specifically indicated in pulmonary arterial hypertension has not been demonstrated in patients with pulmonary parenchymal disorders and associated out-of-proportion pulmonary hypertension, a large number of patients from the present study were treated offlabel on an individual basis, thereby providing some preliminary information on the efficacy and safety of pulmonary hypertension therapy in this condition. No significant effect of treatment was found on survival. However, this result must be interpreted with caution, owing to the retrospective design, heterogeneity of treatment and lack of systematic haemodynamic assessment of the effect of treatment. Whether patients with CPFE and out-of-proportion pre-capillary pulmonary hypertension may benefit from treatment could be best evaluated in randomised controlled trials, although the feasibility of trials is challenged in such a rare and severe condition. Anyway, careful individual evaluation of patients under treatment should be obtained prospectively. Younger patients should be evaluated early for lung transplantation.

Prognostic factors in pulmonary hypertension associated with parenchymal pulmonary disease have not been extensively evaluated. The present study identified high PVR, low cardiac index and low $\mathrm{DL}, \mathrm{CO}$ as significant predictors of a worse prognosis. Several haemodynamic factors associated with a shorter survival in pulmonary arterial hypertension were thus also associated with worse prognosis in this group of patients with CPFE and associated pulmonary hypertension. Other factors associated with a shorter survival in pulmonary arterial hypertension, such as NYHA functional class, 6MWD, pericardial effusion, elevated B-type natriuretic peptide levels and elevated right atrial pressure [34] were not significantly associated with survival in the present study, possibly due to insufficient statistical power.

Our study has several limitations, in particular its observational and uncontrolled design, with retrospective collection of data. Our results are subject to selection and treatment bias. Indication for therapy and choice of drug were not uniform among patients, limiting evaluation of the effect of treatment. Data presented here should not be interpreted as a proper evaluation of efficacy of treatment, which will require specific studies. However, cases of CPFE syndrome were prospectively identified by participating centres; data regarding haemodynamic parameters and survival were unlikely to be affected by the study design. Multivariate analysis could not be performed due to the sample size, and possible confounding effects of various variables related to survival time could not be evaluated. Long-term follow-up was not available in all patients owing to recent diagnosis; patients who were censored for short follow-up were not significantly different at baseline than the rest of the group; given the high mortality rate, it is unlikely that different results would have been found had the whole cohort been followed up for a longer period of time.

In conclusion, pulmonary hypertension may appear within a mean of only 16 months after the diagnosis of CPFE syndrome, mostly in patients requiring long-term oxygen therapy. Prognosis is poor, despite moderately severe haemodynamic parameters, with a 1-yr survival of $60 \%$ from the diagnosis of pulmonary hypertension.

\section{SUPPORT STATEMENT}

Financial support was provided by Hospices Civils de Lyon, Lyon, France ("PHRC regional 2005"; PHRC 2009).

\section{STATEMENT OF INTEREST}

A statement of interest for M. Humbert can be found at www.erj. ersjournals.com $/ \mathrm{misc} /$ statements.dtl

\section{ACKNOWLEDGEMENTS}

Contributors from the GERM"O'”P group: A Berezné (Paris, France), D. Coëtmeur (St-Brieuc, France), I. Danner-Boucher (Nantes, France), D. Funke (Bern, Switzerland), D. Israel-Biet (Paris, France), E. Marchand (Yvoir, Belgium) and L. Mouthon (Paris, France).

The authors are indebted to all physicians who took care of the patients. We thank S. Zeghmar and A.C. Cadoré (Lyon, France) for data extraction and data entry.

\section{REFERENCES}

1 Wiggins J, Strickland B, Turner-Warwick M. Combined cryptogenic fibrosing alveolitis and emphysema: the value of high resolution computed tomography in assessment. Respir Med 1990; 84: 365-369. 
2 Doherty MJ, Pearson MG, O'Grady EA, et al. Cryptogenic fibrosing alveolitis with preserved lung volumes. Thorax 1997; 52: 998-1002.

3 Wells AU, King AD, Rubens MB, et al. Lone cryptogenic fibrosing alveolitis: a functional-morphologic correlation based on extent of disease on thin-section computed tomography. Am J Respir Crit Care Med 1997; 155: 1367-1375.

4 Cottin V, Cordier JF. The syndrome of combined pulmonary fibrosis and emphysema. Chest 2009; 136: 1-2.

5 Cottin V, Nunes H, Brillet PY, et al. Combined pulmonary fibrosis and emphysema: a distinct underrecognised entity. Eur Respir J 2005; 26: 586-593.

6 Rosas IO, Ren P, Avila NA, et al. Early interstitial lung disease in familial pulmonary fibrosis. Am J Respir Crit Care Med 2007; 176: 698-705.

7 Steele MP, Speer MC, Loyd JE, et al. Clinical and pathologic features of familial interstitial pneumonia. Am J Respir Crit Care Med 2005; 172: 1146-1152.

8 Nadrous HF, Pellikka PA, Krowka MJ, et al. Pulmonary hypertension in patients with idiopathic pulmonary fibrosis. Chest 2005; 128: 2393-2399.

9 Patel NM, Lederer DJ, Borczuk AC, et al. Pulmonary hypertension in idiopathic pulmonary fibrosis. Chest 2007; 132: 998-1006.

10 Lettieri CJ, Nathan SD, Barnett SD, et al. Prevalence and outcomes of pulmonary arterial hypertension in advanced idiopathic pulmonary fibrosis. Chest 2006; 129: 746-752.

11 Nathan SD, Shlobin OA, Ahmad S, et al. Pulmonary hypertension and pulmonary function testing in idiopathic pulmonary fibrosis. Chest 2007; 131: 657-663.

12 Shorr AF, Wainright JL, Cors CS, et al. Pulmonary hypertension in patients with pulmonary fibrosis awaiting lung transplant. Eur Respir J 2007; 30: 715-721.

13 Nathan SD, Shlobin OA, Ahmad S, et al. Serial development of pulmonary hypertension in patients with idiopathic pulmonary fibrosis. Respiration 2008; 76: 288-294.

14 Chaouat A, Bugnet AS, Kadaoui N, et al. Severe pulmonary hypertension and chronic obstructive pulmonary disease. Am J Respir Crit Care Med 2005; 172: 189-194.

15 Thabut G, Dauriat G, Stern JB, et al. Pulmonary hemodynamics in advanced COPD candidates for lung volume reduction surgery or lung transplantation. Chest 2005; 127: 1531-1536.

16 Chaouat A, Naeije R, Weitzenblum E. Pulmonary hypertension in COPD. Eur Respir J 2008; 32: 1371-1385.

17 Hamada K, Nagai S, Tanaka S, et al. Significance of pulmonary arterial pressure and diffusion capacity of the lung as prognosticator in patients with idiopathic pulmonary fibrosis. Chest 2007; 131: 650-656.

18 Oswald-Mammosser M, Weitzenblum E, Quoix E, et al. Prognostic factors in COPD patients receiving long-term oxygen therapy. Importance of pulmonary artery pressure. Chest 1995; 107: 1193-1198.

19 Mejia M, Carrillo G, Rojas-Serrano J, et al. Idiopathic pulmonary fibrosis and emphysema: decreased survival associated with severe pulmonary arterial hypertension. Chest 2009; 136: 10-15.
20 Simonneau G, Robbins IM, Beghetti M, et al. Updated clinical classification of pulmonary hypertension. J Am Coll Cardiol 2009; 54: S43-S54.

21 American Thoracic Society/European Respiratory Society International Multidisciplinary Consensus Classification of the Idiopathic Interstitial Pneumonias. Am J Respir Crit Care Med 2002; 165: 277-304.

22 Galie N, Torbicki A, Barst R, et al. Guidelines on diagnosis and treatment of pulmonary arterial hypertension. The Task Force on Diagnosis and Treatment of Pulmonary Arterial Hypertension of the European Society of Cardiology. Eur Heart J 2004; 25: 22432278.

23 McGoon M, Gutterman D, Steen V, et al. Screening, early detection, and diagnosis of pulmonary arterial hypertension: ACCP evidencebased clinical practice guidelines. Chest 2004; 126: 14S-34S.

24 ATS statement: guidelines for the six-minute walk test. Am J Respir Crit Care Med 2002; 166: 111-117.

25 Quanjer PH, Tammeling GJ, Cotes JE, et al. Lung volumes and forced ventilatory flows. Report Working Party Standardization of Lung Function Tests, European Community for Steel and Coal. Official Statement of the European Respiratory Society. Eur Respir J Suppl 1993; 16: 5-40.

26 Sitbon $\mathrm{O}$, Humbert $\mathrm{M}$, Jais $\mathrm{X}$, et al. Long-term response to calcium channel blockers in idiopathic pulmonary arterial hypertension. Circulation 2005; 111: 3105-3111.

27 Aduen JF, Zisman DA, Mobin SI, et al. Retrospective study of pulmonary function tests in patients presenting with isolated reduction in single-breath diffusion capacity: implications for the diagnosis of combined obstructive and restrictive lung disease. Mayo Clin Proc 2007; 82: 48-54.

28 Fisher MR, Criner GJ, Fishman AP, et al. Estimating pulmonary artery pressures by echocardiography in patients with emphysema. Eur Respir J 2007; 30: 914-921.

29 Nathan SD, Shlobin OA, Barnett SD, et al. Right ventricular systolic pressure by echocardiography as a predictor of pulmonary hypertension in idiopathic pulmonary fibrosis. Respir Med 2008 102: $1305-1310$.

30 Arcasoy SM, Christie JD, Ferrari VA, et al. Echocardiographic assessment of pulmonary hypertension in patients with advanced lung disease. Am J Respir Crit Care Med 2003; 167: 735-740.

31 King TE Jr, Tooze JA, Schwarz MI, et al. Predicting survival in idiopathic pulmonary fibrosis: scoring system and survival model. Am J Respir Crit Care Med 2001; 164: 1171-1181.

32 Humbert M, Sitbon O, Chaouat A, et al. Pulmonary arterial hypertension in France: results from a National Registry. Am J Respir Crit Care Med 2006; 173: 1023-1030.

33 Treatment of pulmonary hypertension in chronic obstructive pulmonary disease. In: Siafakas NM, ed. Management of Chronic Obstructive Pulmonary Disease. Eur Respir Mon 2006; 38: 313-324

34 McLaughlin VV, Presberg KW, Doyle RL, et al. Prognosis of pulmonary arterial hypertension: ACCP evidence-based clinical practice guidelines. Chest 2004; 126: 78S-92S. 